Check for updates

Cite this: RSC Adv., 2019, 9, 38038

Received 11th August 2019

Accepted 11th November 2019

DOI: 10.1039/c9ra06250e

rsc.li/rsc-advances

\title{
Branched polyethyleneimine-assisted 3- carboxybenzoboroxole improved Wulff-type boronic acid functionalized magnetic nanoparticles for the specific capture of cis-diol-containing flavonoids under neutral conditions
}

Daojin Li, (D) * Zheyao Liu, Rumeng Song, Wenliu Yang, Simeng Zhai and Wenhui Wang

\begin{abstract}
Flavonoids have shown a variety of biological activities such as antimicrobial, antibacterial, antifungal, antiviral, antiinflammatory, antitumor, antiatherogenic, and antihyperglycemic activities. A lot of important flavonoids contain cis-diols such as rutin (Ru), quercetin (Qu), luteolin (Lu), myricetin (Myr) and baicalein ( $\mathrm{Ba}$ ) and so on. It is necessary to establish a simple, low-cost and efficient purification method for cis-diol-containing flavonoids from plant extracts. Boronate affinity materials are able to reversibly bind the cis-diols via boronic acids by forming a five- or six-membered boronic cyclic ester in aqueous media. However, conventional boronate affinity materials have to be used in alkaline media, which can lead to the oxidation of cis-diols in compounds. In this study, the polyethyleneimine (PEI)-assisted 3carboxybenzoboroxole-functionalized magnetic nanoparticles (MNPs) were prepared to achieve efficient capture of cis-diol-containing flavonoids under neutral conditions. Branched PEI was applied as a scaffold to amplify the number of boronic acid moieties, while 3-carboxybenzoboroxole, exhibiting high affinity and excellent water solubility toward flavonoids, was used as an affinity ligand. The prepared boronate affinity MNPs exhibited high binding capacity and fast binding kinetics (equilibrium in $3 \mathrm{~min}$ ) under neutral conditions. In addition, the obtained boronate affinity MNPs exhibited high binding affinity $\left(K_{\mathrm{d}} \approx 10^{-4} \mathrm{M}\right)$, low binding $\mathrm{pH}(\mathrm{pH} \geq 6.0)$ and tolerance of the interference to abundant sugars.
\end{abstract}

\section{Introduction}

Flavonoids are plant-derived dietary components defined by a diphenylpropane (C6-C3-C6) skeleton, which consist of a large group of heterogeneous polyphenols. ${ }^{1,2}$ Flavonoids can be found in fruits, vegetables, herbaceous plants, flowers, tea, honey, coffee and wine, etc. ${ }^{3}$ Pharmacological studies of flavonoids have shown a variety of biological activities such as antimicrobial, antibacterial, antifungal, antiviral, antiinflammatory, antitumor, antiatherogenic, antihyperglycemic activities and fighting acetaminophen-mediated hepatotoxicity, especially antioxidant activities..$^{4-9}$ Many biological and pharmacological properties of flavonoids are associated with free radical-scavenging actions because free radicals are considered to be important causative factors in the development of various diseases..$^{10}$ Clearly, flavonoids are highly beneficial for human health via interacting with a number of cellular targets involved in critical cell signalling pathways in the body. A lot of flavonoids contain cis-diols such as rutin, quercetin, luteolin,

College of Chemistry and Chemical Engineering, Henan Key Laboratory of Function-Oriented Porous Materials, Luoyang Normal University, Luoyang 471022, P. R. China. E-mail: lidaojin7910@126.com myricetin, fisetin, leptosidin, aureusidin and baicalein, and so on. The type of cis-diol-containing flavonoids is unique classes of flavonoids, which exhibits a variety of biological activities. Therefore, it is extremely important to determine cis-diolcontaining flavonoids in real samples such as fruits, vegetables, herbaceous plants, flowers, tea, honey, coffee, wine and so on. Spectrophotometric methods are suitable for determining cis-diol-containing flavonoids because the equipment is simple and easy to operate. However, some interfering components in the sample matrix affect the analysis. Therefore, it is necessary to establish a simple, low-cost and efficient purification method for cis-diol-containing flavonoids from plant extracts.

Boronate affinity is a unique means for the selective extraction and separation of cis-diol-containing compounds. ${ }^{11-37}$ Boronic acids are able to covalently interact with cis-diolcontaining compounds to form five- or six-membered cyclic esters usually under alkaline $\mathrm{pH}$ conditions and the cyclic esters dissociate when the environmental $\mathrm{pH}$ is changed to acidic. However, the use of alkaline media is easy to oxidize the cisdiols of cis-diol-containing flavonoids. ${ }^{38}$ In addition, the discharge of alkaline aqueous solution may cause secondary pollution in water, which requires additional separation treatments. Thus, boronic acid-functionalized materials that can 
function at neutral $\mathrm{pH}$ would be highly desirable for the separation and purification of cis-diol-containing flavonoids. As far as we know, a variety of attempts have been made to reduce the binding $\mathrm{pH}$. Up to date, four types of boronic acid monomers with low $\mathrm{p} K_{\mathrm{a}}$ values can provide low binding $\mathrm{pH}$ : (1) boronic acid ligands with electron-withdrawing groups, such as nitro, fluoro and sulfonyl on the phenyl ring; ${ }^{39,40}$ (2) Wulff-type boronic acids, which contain intramolecular tetracoordinated B-N or B-O bonds; ${ }^{\mathbf{4 1 , 4 2}}$ (3) improved Wulff-type boronic acids, which contain intramolecular tricoordinated $\mathrm{B}-\mathrm{O}$ bonds; ${ }^{\mathbf{4 3 , 4 4}}$ and (4) heterocyclic boronic acids. ${ }^{4,46}$ The above mentioned structures of boronic acid ligands can be used to prepare boronate affinity materials with low binding $\mathrm{pH}$. Among them, improved Wulff-type boronic acids, which are called benzoboroxoles, contain intramolecular tricoordinated $\mathrm{B}-\mathrm{O}$ bonds rather than the classical intramolecular tetracoordinated $\mathrm{B}-\mathrm{N}$ or B-O bonds in the molecular structure. Due to their unique structure, benzoboroxoles display the advantages of a low $\mathrm{p} K_{\mathrm{a}}$ value (7.3), excellent hydrophilicity and improved cis-diol binding capability under neutral conditions. Among the benzoboroxoles family, 3-carboxybenzoboroxole possesses lower $\mathrm{p} K_{\mathrm{a}}$ value (6.9) and higher affinity to cis-diol-containing compounds due to the electron-withdrawing effect of carboxyl. ${ }^{47}$ Therefore, 3-carboxybenzoboroxole is considered as a powerful ligand to prepare boronate affinity materials. For example, researchers have prepared boronate affinity monolithic column through using the improved Wulff-type boronic acids as ligand for the selective capture of nucleosides/ glycoproteins/glycopeptides under neutral or acidic conditions. ${ }^{47-49}$ However, such materials have not been used in the large-scale cis-diol-containing flavonoids enrichment. In addition, the binding capacity of monolithic columns is usually lower than that of nonmaterial. Therefore, the development of 3-carboxybenzoboroxole-functionalized nanomaterials might be of great significance to achieve efficient capture of cis-diolcontaining flavonoids under neutral or acidic conditions. There is no report about boronic acid-functionalized nanomaterials resulted from improved Wulff-type boronic acids for capture of cis-diol-containing flavonoids.

However, the binding capacity of single boronic acids functionalized materials toward cis-diol-containing compounds is relatively low. Through amplification of the number of boronic acid moieties using highly branched poly(amidoamine) (PAMAM) dendrimers or polyethyleneimine (PEI), the boronic acid functionalized materials exhibited a significantly improved binding capacity. Compared with PAMAM, the branched PEI can be used as a better scaffold to amplify the number of boronic acid moieties because of its flexible chains, hydrophilic properties, easy post-modification, plentiful amino groups and low cost. Thus, it is essential to develop PEI-assisted improved boronic acids-functionalized nanomaterials for the specific capture of cis-diol-containing flavonoids under neutral $\mathrm{pH}$ condition.

In the study, we applied 3-carboxybenzoboroxole as ligands to prepare PEI-assisted boronic acid-functionalized magnetic nanoparticles (MNPs) for highly efficient capture of cis-diolcontaining flavonoids under neutral condition. In this work, magnetic $\mathrm{Fe}_{3} \mathrm{O}_{4}$ nanoparticles were used as supporting nanomaterials due to their good biocompatibility, superparamagnetic property, low toxicity and easy preparation. Firstly, amino-functionalized MNPs were synthesized and then PEI modified MNPs were prepared. Subsequently, PEI modified MNPs were functionalized with boronic acid by the amidation between amino of PEI and carboxyl of 3-carboxybenzoboroxole. Due to the PEI-amplified boronic acid sites, the binding capacity of the obtained PEI-assisted boronic acidfunctionalized MNPs was significantly enhanced. The prepared boronate affinity MNPs exhibited fast binding kinetics (equilibrium in $3 \mathrm{~min}$ ) under neutral condition. In addition, the obtained boronate affinity MNPs exhibited high binding affinity $\left(K_{\mathrm{d}} \approx 10^{-4} \mathrm{M}\right)$ and low binding $\mathrm{pH}(\mathrm{pH} \geq 6.0)$.

\section{Experimental}

\section{Reagents and materials}

Branched polyethyleneimine (PEI) $\left(M_{\mathrm{w}}=600,1800,10000\right.$ and 70 000), 3-carboxybenzoboroxole (CBO), rutin (Ru), quercetin $(\mathrm{Qu})$, luteolin $(\mathrm{Lu})$, myricetin (Myr), genistein (Gen), isorhamnetin (Iso), and kaempferol (Kae) were from J\&K Scientific (Shanghai, China). Ferric chloride hexahydrate $\left(\mathrm{FeCl}_{3} \cdot 6 \mathrm{H}_{2} \mathrm{O}\right)$, anhydrous sodium acetate (NaOAc), ethylene glycol, sodium cyanoborohydride, anhydrous methanol, glutaraldehyde, 1,6hexanediamine, 1-ethyl-3-(3-dimethylaminopropyl) carbodiimide (EDC) and $\mathrm{N}$-hydroxysuccinimide (NHS) were purchased from Alfa Aesar (Tianjin, China). All used reagents were of analytical grade. All commercially available reagents were used without further purification. Water used in all the experiments was purified by a Milli-Q Advantage A10 ultrapure purification system (Millipore, Milford, USA).

\section{Instruments}

Transmission electron microscopy (TEM) was performed on a JEM-1010 system (JEOL, Tokyo, Japan). Powder X-ray diffraction (XRD) analyses were carried out using a Bruker D8 Advance diffractometer with $\mathrm{Cu} \mathrm{K} \alpha$ radiation and the scanning angle ranged from $10^{\circ}$ to $80^{\circ}$ of $2 \theta$. UV absorbance data were acquired from a U-3010 UV spectrophotometer equipped a $1 \mathrm{~cm}$ cuvette (Kyoto, Japan). The magnetic properties were measured with a vibrating sample magnetometer (VSM) (LDJ 9600-1, USA). The magnetic properties were measured with a vibrating sample magnetometer (VSM) (LDJ 9600-1, USA).

\section{Preparation of $\mathrm{Fe}_{3} \mathrm{O}_{4} @ P E I @ C B O$}

The procedure for the synthesis of $\mathrm{Fe}_{3} \mathrm{O}_{4} @ P E I @ C B O$ was depicted in Fig. 1. It included three steps: (1) synthesis of amino-functionalized magnetic nanoparticles $\left(\mathrm{Fe}_{3} \mathrm{O}_{4} \mathrm{NPs}\right),(2)$ preparation of PEI modified MNPs $\left(\mathrm{Fe}_{3} \mathrm{O}_{4} @ \mathrm{PEI}\right)$, and (3) functionalization with 3-carboxybenzoboroxole (CBO). The $\mathrm{Fe}_{3} \mathrm{O}_{4}$ NPs were synthesized based on a previously reported method ${ }^{50}$ with minor modification. Briefly, ferric trichloride hexahydrate $(2.0 \mathrm{~g})$ was first dissolved in ethylene glycol $(60 \mathrm{~mL})$ to form a clear orange yellow color solution. Then, anhydrous sodium acetate $(4.0 \mathrm{~g})$ and 1,6-hexanediamine $(13.0 \mathrm{~g})$ was added to the 

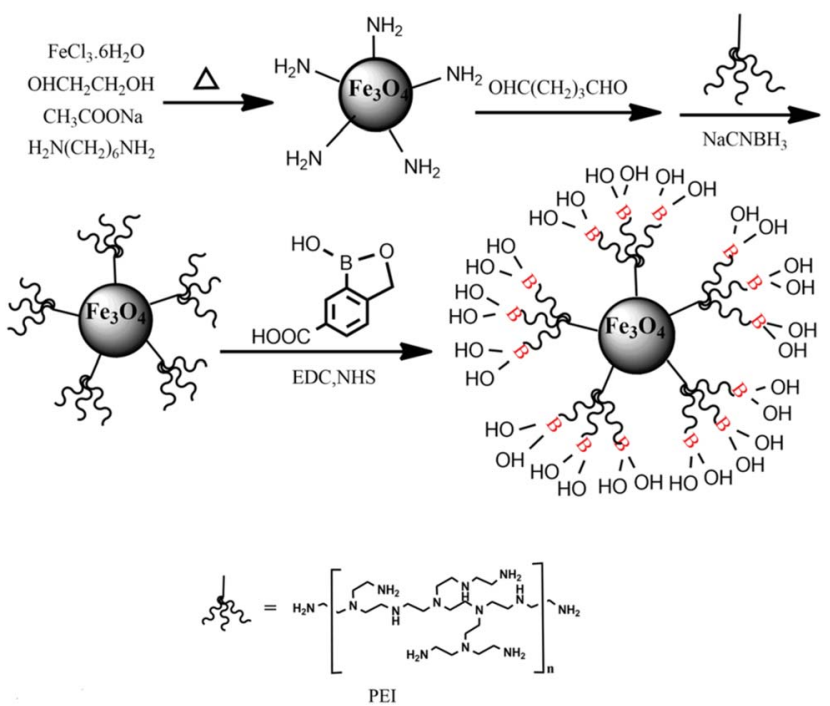

Fig. 1 Synthesis routes of $\mathrm{Fe}_{3} \mathrm{O}_{4}$ (aPEI aCBO

above solution. Finally, the mixture was stirred vigorously for $40 \mathrm{~min}$ and sealed in a PTFE-lined autoclave and reacted at $198{ }^{\circ} \mathrm{C}$ for $6 \mathrm{~h}$. The resulting $\mathrm{Fe}_{3} \mathrm{O}_{4}$ NPs were rinsed with water and ethanol for 3 times each, and then dried at $50{ }^{\circ} \mathrm{C}$ in a vacuum overnight. After $200 \mathrm{mg} \mathrm{Fe}_{3} \mathrm{O}_{4}$ NPs were added to $40 \mathrm{~mL}$ anhydrous methanol containing $5 \%$ glutaraldehyde, the mixture was mechanically stirred for $12 \mathrm{~h}$ at room temperature. The resulting glutaraldehyde-activated $\mathrm{Fe}_{3} \mathrm{O}_{4} \mathrm{NPs}$ were collected by a magnet and then dispersed in $40 \mathrm{~mL}$ anhydrous methanol containing $0.6 \mathrm{~g}$ PEI by ultrasound. The mixture was mechanically stirred $(600 \mathrm{rpm})$ for $12 \mathrm{~h}$ at room temperature. After that, $15 \mathrm{mg} \mathrm{mL} \mathrm{m}^{-1}$ sodium cyanoborohydride was added $(200 \mathrm{mg}$ every 6 hours) during the course of reaction for $24 \mathrm{~h}$. The $\mathrm{Fe}_{3}$ $\mathrm{O}_{4} @ \mathrm{PEI}$ were collected by a magnet and washed with water and ethanol for 3 times each, and then dried at $50{ }^{\circ} \mathrm{C}$ overnight. To carry out boronic acid-functionalization of $\mathrm{Fe}_{3} \mathrm{O}_{4} @ P E I, 30 \mathrm{mg}$ of $\mathrm{Fe}_{3} \mathrm{O}_{4} @ P E I$ was first dispersed into $30 \mathrm{~mL}$ of $50 \mathrm{mM}$ phosphate buffer ( $\mathrm{pH}$ 7.4), and then the solution was ultrasonicated for $3 \mathrm{~min}$. After that, $270 \mathrm{mg}$ of EDC and $140 \mathrm{mg}$ of NHS were added into the solution. After ultrasonicated for $20 \mathrm{~s}$, the obtained solution was vigorously stirred for $40 \mathrm{~min}$ at $25{ }^{\circ} \mathrm{C}$. After that, $100 \mathrm{mg}$ of CBO was added and the mixture was kept shaking for $20 \mathrm{~min}$ at $25^{\circ} \mathrm{C}$ and then kept at room temperature for $24 \mathrm{~h}$. The $\mathrm{Fe}_{3} \mathrm{O}_{4} @ \mathrm{PEI} @ \mathrm{CBO}$ was separated from reaction mixtures using a magnet and washed with water and ethanol and dried at $50{ }^{\circ} \mathrm{C}$. The obtained $\mathrm{Fe}_{3} \mathrm{O}_{4} @ \mathrm{PEI} @ \mathrm{CBO}$ was stored for further use.

\section{Selectivity of $\mathrm{Fe}_{3} \mathrm{O}_{4} @ P E I @ C B O$}

The selectivity of $\mathrm{Fe}_{3} \mathrm{O}_{4} @ \mathrm{PEI} @ \mathrm{CBO}$ was evaluated using rutin $(\mathrm{Ru})$, quercetin $(\mathrm{Qu})$, luteolin ( $\mathrm{Lu})$ and myricetin (Myr) as cisdiol-containing test flavonoids while genistein (Gen), isorhamnetin (Iso), and kaempferol (Kae) were used as non-cis-diol analogue. First, a solution for each flavonoid of $0.5 \mathrm{mg} \mathrm{mL}$ was separately prepared with $50 \mathrm{mM}$ phosphate buffer $(\mathrm{pH} 7.0)$. Then equivalent $\mathrm{Fe}_{3} \mathrm{O}_{4} @ \mathrm{PEI} @ \mathrm{CBO}$ were added to $500 \mu \mathrm{L}$ of the flavonoid solutions in centrifugal tubes, respectively. Then, the centrifugal tubes were shaken on a rotator at room temperature for $2 \mathrm{~h}$. The $\mathrm{Fe}_{3} \mathrm{O}_{4}$ @PEI@CBO were then collected at the tube wall by applying a magnet and rinsed with $500 \mu \mathrm{L}$ of $50 \mathrm{mM}$ sodium phosphate buffer $(\mathrm{pH}$ 7.0) for three times. After washing, the MNPs were re-suspended and eluted in $100 \mu \mathrm{L}$ of acetic acid solution for $1 \mathrm{~h}$ on a rotator. Finally, the MNPs were trapped to the tube wall by using a magnet and the eluates were collected. The amounts of these flavonoids adsorbed by the $\mathrm{Fe}_{3} \mathrm{O}_{4} @ \mathrm{PEI} @ \mathrm{CBO}$ were determined by measuring the eluates in terms of UV absorbance at maximum absorption wavelength. The measurement was repeated with three times.

\section{Kinetic adsorption experiment}

$0.50 \mathrm{mg} \mathrm{mL} \mathrm{m}^{-1}$ of rutin or quercetin dissolved in $50 \mathrm{mM}$ phosphate buffer ( $\mathrm{pH}$ 7.0) was applied as a representative sample. The kinetic adsorption experiment was performed as follows: the suspension containing $3 \mathrm{mg} \mathrm{Fe}_{3} \mathrm{O}_{4} @ \mathrm{PEI} @ \mathrm{CBO}$ was added to $0.5 \mathrm{~mL}$ of rutin or quercetin solution and shaken different durations from 1 to $14 \mathrm{~min}$ at room temperature. The MNPs were collected by using external magnetic force and rinsed with $500 \mu \mathrm{L}$ of $50 \mathrm{mM}$ phosphate buffer ( $\mathrm{pH}$ 7.0) for three times. After washing, rutin or quercetin bound on $\mathrm{Fe}_{3} \mathrm{O}_{4} @ P E I @ C B O$ was eluted in $100 \mu \mathrm{L}$ acetic acid solutions ( $\mathrm{pH}$ 2.7) for $1 \mathrm{~h}$ on a rotator and the concentration of rutin or quercetin in the supernatant was measured by absorbance analysis.

\section{Measurement of adsorption isotherm and Scatchard analysis}

The measurement of adsorption isotherm was performed according to the following process. Briefly, $\mathrm{Fe}_{3} \mathrm{O}_{4} @ \mathrm{PEI} @ \mathrm{CBO}$ was first dispersed to $50 \mathrm{mM}$ phosphate buffer to homogenize the NPs (15 mg mL ${ }^{-1}$ ). After $\mathrm{Fe}_{3} \mathrm{O}_{4} @ P E I @ C B O$ of the above suspension $(200 \mu \mathrm{L})$ were collected by a magnet, $300 \mu \mathrm{L}$ solutions of different concentrations of rutin or quercetin were added to the above $\mathrm{Fe}_{3} \mathrm{O}_{4} @ \mathrm{PEI} @ \mathrm{CBO}$ and shaken on a rotator for $1 \mathrm{~h}$ at room temperature. Thereafter, $\mathrm{Fe}_{3} \mathrm{O}_{4} @ \mathrm{PEI} @ \mathrm{CBO}$ with trapped rutin or quercetin were separated by using an external magnetic force and then washed with $300 \mu \mathrm{L}$ of $50 \mathrm{mM}$ sodium phosphate buffer $(\mathrm{pH}$ 7.4) for 3 times each. Finally, the components bound on the NPs were eluted by $100 \mathrm{mM}$ acetic acid solution. The eluent containing rutin or quercetin adsorbed by the NPs was measured with UV-vis spectrophotometer.

The Scatchard analysis was implemented according to a previously reported method. ${ }^{43}$ Dissociation constant $\left(K_{\mathrm{d}}\right)$ and apparent maximum binding capacity $\left(Q_{\max }\right)$ were evaluated according to the following Scatchard equation:

$$
\frac{Q_{\mathrm{e}}}{C_{\mathrm{s}}}=\frac{Q_{\max }}{K_{\mathrm{d}}}-\frac{Q_{\mathrm{e}}}{K_{\mathrm{d}}}
$$

where $Q_{\max }$ and $K_{\mathrm{d}}$ is the saturated binding capacity and the dissociation constant, respectively, $Q_{\mathrm{e}}$ is the binding amount of rutin or quercetin to $\mathrm{Fe}_{3} \mathrm{O}_{4} @ \mathrm{PEI} @ \mathrm{CBO}$ at equilibrium, $C_{\mathrm{s}}$ is the free concentration at adsorption equilibrium. The values for $K_{\mathrm{d}}$ and $Q_{\max }$ can be calculated from the slope and the intercept of plots of $Q_{\mathrm{e}} / C_{\mathrm{s}}$ versus $Q_{\mathrm{e}}$. 


\section{Reproducibility and reusability}

The experiment on reproducibility of $\mathrm{Fe}_{3} \mathrm{O}_{4} @ \mathrm{PEI} @ \mathrm{CBO}$ was carried out through adding $3 \mathrm{mg}$ of five batches of dry products prepared on different time into $0.3 \mathrm{~mL}$ of rutin or quercetin solution at a concentration of $0.50 \mathrm{mg} \mathrm{mL}^{-1}$. The remaining steps were the same as binding isotherm experiment. To estimate the reusability of $\mathrm{Fe}_{3} \mathrm{O}_{4} @ \mathrm{PEI} @ \mathrm{CBO}, 3 \mathrm{mg}$ of dry MNPs was added to $0.3 \mathrm{~mL}$ of rutin or quercetin solution at a concentration of $0.50 \mathrm{mg} \mathrm{mL}^{-1}$ and incubated for 30 minutes at room temperature. Then, the products were separated by an external magnet. The recovered NPs were washed with $5 \mathrm{~mL}$ acetonitrileacetic acid $(1 / 2, \mathrm{v} / \mathrm{v})$ for 2 hours to ensure complete removal of the residual quercetin in $\mathrm{Fe}_{3} \mathrm{O}_{4} @ \mathrm{PEI} @ \mathrm{CBO} . \mathrm{Fe}_{3} \mathrm{O}_{4} @ \mathrm{PEI} @ \mathrm{CBO}$ were washed with water several times, then dried under vacuum overnight and reused for the adsorption of rutin or quercetin again. The adsorption-regeneration cycle was repeated ten times with the same $\mathrm{Fe}_{3} \mathrm{O}_{4} @ \mathrm{PEI} @ \mathrm{CBO}$.

\section{Results and discussion}

\section{Characterization of the magnetic nanoparticles (MNPs)}

The morphology of the prepared MNPs was characterized by transmission electron microscopy (TEM). As depicted in Fig. 2A, TEM images of $\mathrm{Fe}_{3} \mathrm{O}_{4} @ P E I @ C B O$ revealed that the MNPs had good dispersibility and relatively homogeneous size

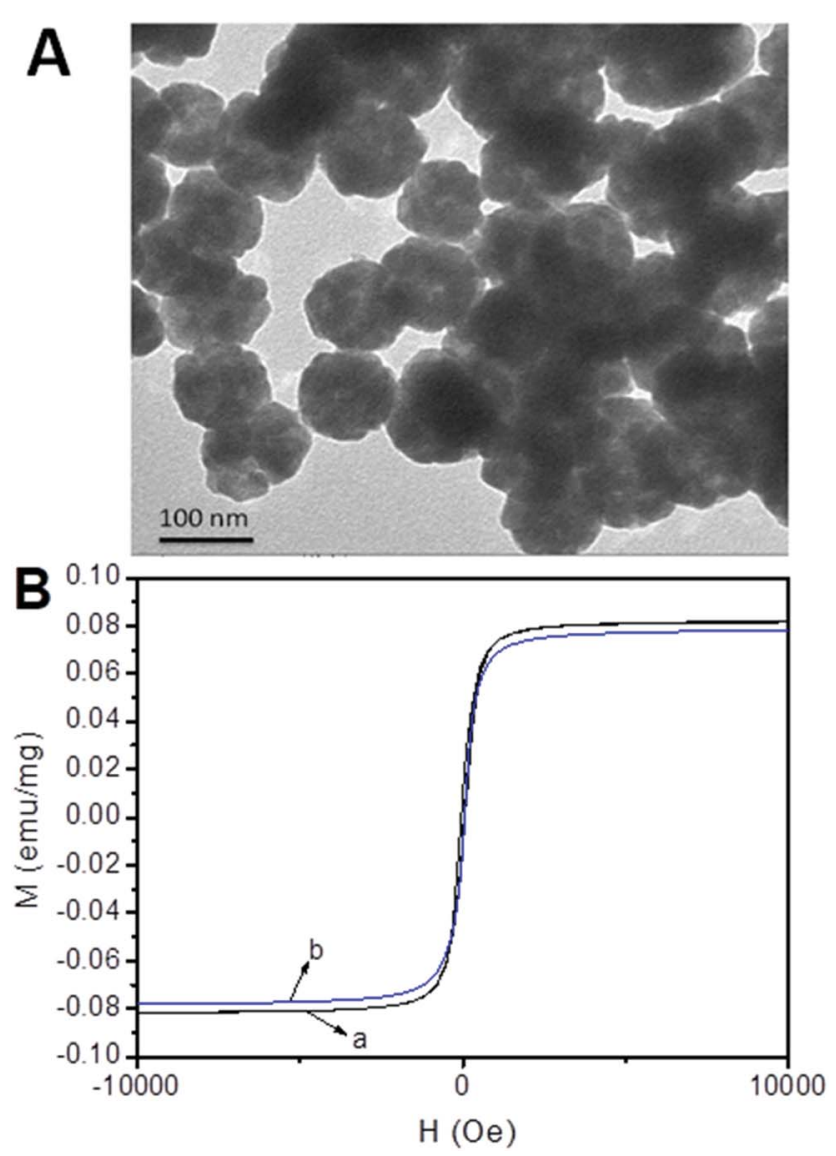

Fig. 2 TEM images of $\mathrm{Fe}_{3} \mathrm{O}_{4}$ (PEI@CCBO and magnetic hysteresis curves of bare MNPs (A) and $\mathrm{Fe}_{3} \mathrm{O}_{4}(\mathrm{aPEl}(\mathrm{aCBO}(\mathrm{B})$. distribution. The average diameter of the $\mathrm{Fe}_{3} \mathrm{O}_{4} @ P E I @ C B O$ was estimated to be about $100 \mathrm{~nm}$. The magnetization of the bare MNPs and $\mathrm{Fe}_{3} \mathrm{O}_{4} @ P E I @ C B O$ was measured using VSM and the resulting magnetic hysteresis curves are shown in Fig. 2B. The saturation magnetizations of bare $\mathrm{MNPs}$ and $\mathrm{Fe}_{3} \mathrm{O}_{4} @ \mathrm{PEI} @ \mathrm{CBO}$

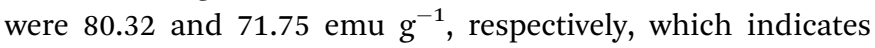
superparamagnetic behavior. The decrease of the saturation magnetization of $\mathrm{Fe}_{3} \mathrm{O}_{4} @ \mathrm{PEI} @ \mathrm{CBO}$ in comparison with bare MNPs results from the formed modification layers, which could shield the magnetite to some extent. The crystalline nature of $\mathrm{Fe}_{3} \mathrm{O}_{4} @ \mathrm{PEI} @ \mathrm{CBO}$ has also been confirmed by XRD analysis (Fig. 3), considering the several sharp peaks corresponding to the crystalline planes of cubic spinel nanostructure of the magnetic nanoparticles.

\section{Selectivity}

The selectivity of the obtained $\mathrm{Fe}_{3} \mathrm{O}_{4} @ \mathrm{PEI} @ \mathrm{CBO}$ was first investigated using rutin $(\mathrm{Ru})$, quercetin $(\mathrm{Qu})$, luteolin $(\mathrm{Lu})$ and myricetin (Myr) as cis-diol-containing test flavonoids and genistein (Gen), isorhamnetin (Iso), and kaempferol (Kae) as noncis-diol analogue. As depicted in Fig. 4, $\mathrm{Fe}_{3} \mathrm{O}_{4} @ \mathrm{PEI} @ \mathrm{CBO}$ exhibited higher binding capacity for cis-diol-containing flavonoids than that for non-cis-diol flavonoids, which indicated good selectivity.

\section{Optimization of the molecular weight of PEI}

Generally, the larger the molecular weight of PEI is, the more amine groups it can provide. However, once the molecular weight of PEI exceeds a certain value, a portion of amine groups may become inaccessible. Thus, it is necessary to investigate the effect of the molecular weight of PEI on the number of the binding sites. The number of the binding sites can be reflected by binding capacity $\left(Q, \mathrm{mg} \mathrm{g}^{-1}\right)$. To determine which molecular weight of PEI can obtain the highest binding capacity, we investigated the effect of the chain length of PEI on the binding capacity. It should be noted that the amount of functional monomer can be guaranteed to be excess. We investigated which amount of functional monomer is excess for the adsorption capacity before optimizing the molecular weight of PEI. As depicted in Fig. 5, the binding capacity increased with

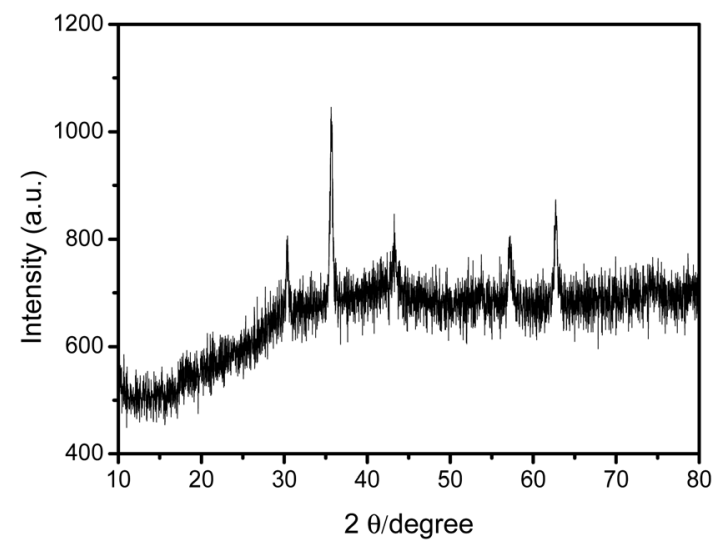

Fig. 3 XRD pattern of $\mathrm{Fe}_{3} \mathrm{O}_{4}$ @PEl@CBO. 


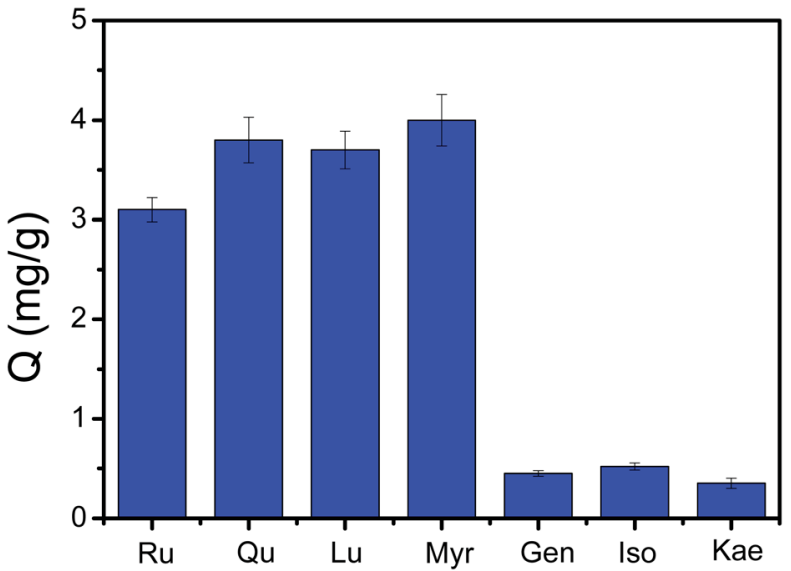

Fig. 4 Comparison of the amount of different analytes captured by $\mathrm{Fe}_{3} \mathrm{O}_{4} \mathrm{QPEI} \mathrm{aCBO}$. Binding buffer: $50 \mathrm{mM}$ sodium phosphate buffer ( $\mathrm{pH}$ 7.0); elution solution: $100 \mathrm{mM} \mathrm{HAc}(\mathrm{pH}$ 2.7); samples: $0.50 \mathrm{mg}$ $\mathrm{mL}^{-1} \mathrm{Ru}, \mathrm{Qu}, \mathrm{Lu}, \mathrm{Myr}, \mathrm{Gen}$, Iso, or Kae dissolved in binding buffer.

the increase of molecular weight of PEI from 600 to 10000 regardless of Ru or Qu. However, when PEI 70,000 was used, the binding capacity is lower than that when using PEI 10000. The
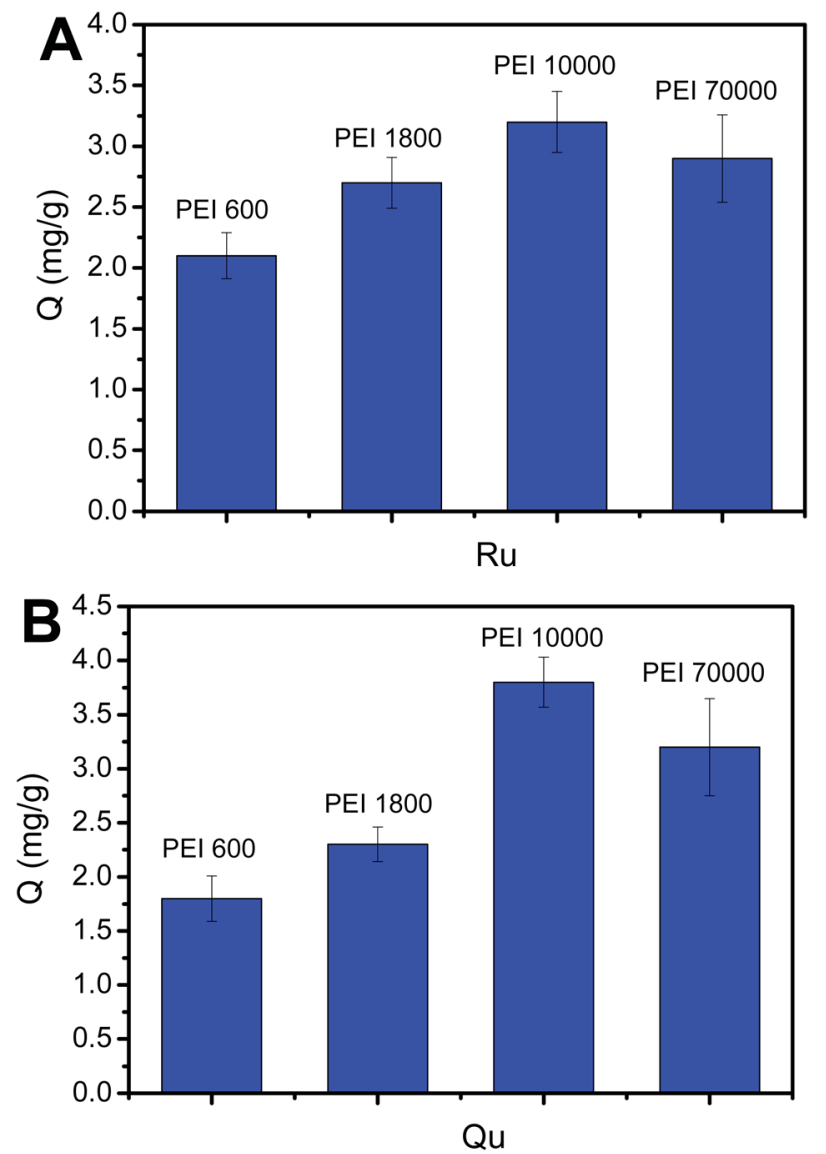

Fig. 5 Comparison of the amount of $\mathrm{Ru}(\mathrm{A})$ and $\mathrm{Qu}$ (B) samples captured by $\mathrm{Fe}_{3} \mathrm{O}_{4} \mathrm{QPEI} @ \mathrm{CBO}$ through changing molecular weight of PEI. Binding buffer: $50 \mathrm{mM}$ sodium phosphate buffer ( $\mathrm{pH}$ 7.0); elution solution: $100 \mathrm{mM} \mathrm{HAc}\left(\mathrm{pH}\right.$ 2.7); samples: $0.50 \mathrm{mg} \mathrm{mL}^{-1}$ rutin (Ru) quercetin $(\mathrm{Qu})$.
PEI 10,000-modified 3-carboxybenzoboroxole-functionalized MNPs were considered as the optimal $\mathrm{Fe}_{3} \mathrm{O}_{4} @ P E I @ C B O$ for further investigations and application.

\section{Determination of $Q_{\max }$ and $K_{\mathrm{d}}$}

Binding capacity is a crucial factor in boronate affinity materials. It determines the maximum amount of targets that an affinity material can capture. On the other hand, binding affinity is an important binding property of boronate affinity materials, which can determine how low the concentrations of cis-diol-containing flavonoids can be enriched by $\mathrm{Fe}_{3} \mathrm{O}_{4}$ @PEI@CBO. The maximum binding capacity $\left(Q_{\max }\right)$ and dissociation constant $\left(K_{\mathrm{d}}\right)$ of $\mathrm{Fe}_{3} \mathrm{O}_{4} @ \mathrm{PEI} @ \mathrm{CBO}$ with rutin $\left(M_{\mathrm{w}}: 610\right)$ and quercetin $\left(M_{\mathrm{w}}: 302\right)$ were evaluated using UV-vis spectrophotometry.

We first investigated binding capacity and binding strength of $\mathrm{Fe}_{3} \mathrm{O}_{4} @ \mathrm{PEI} @ \mathrm{CBO}$ toward rutin. As shown in Fig. 6, according to binding isotherms and Scatchard plots analyses, $Q_{\max }$ and $K_{\mathrm{d}}$ values of $\mathrm{Fe}_{3} \mathrm{O}_{4} @ \mathrm{PEI} @ \mathrm{CBO}$ were calculated to be $(3.21 \pm$ $0.23) \mathrm{mg} \mathrm{g}^{-1}$ and $(1.01 \pm 0.10) \times 10^{-4} \mathrm{M}$, respectively. We further investigated the binding capacity and binding strength of the $\mathrm{Fe}_{3} \mathrm{O}_{4} @ \mathrm{PEI} @ \mathrm{CBO}$ toward quercetin. The binding isotherms and Scatchard plots for quercetin were shown in Fig. 7. The $Q_{\max }$ and $K_{\mathrm{d}}$ values of $\mathrm{Fe}_{3} \mathrm{O}_{4} @ \mathrm{PEI} @ \mathrm{CBO}$ were evaluated to be $(4.29 \pm 0.21) \mathrm{mg} \mathrm{g}^{-1}$ and $(3.62 \pm 0.21) \times 10^{-4} \mathrm{M}$, respectively. Clearly, the rutin exhibited nearly four folds lower $K_{\mathrm{d}}$ value than quercetin for $\mathrm{Fe}_{3} \mathrm{O}_{4} @ \mathrm{PEI} @ \mathrm{CBO}$. This possible
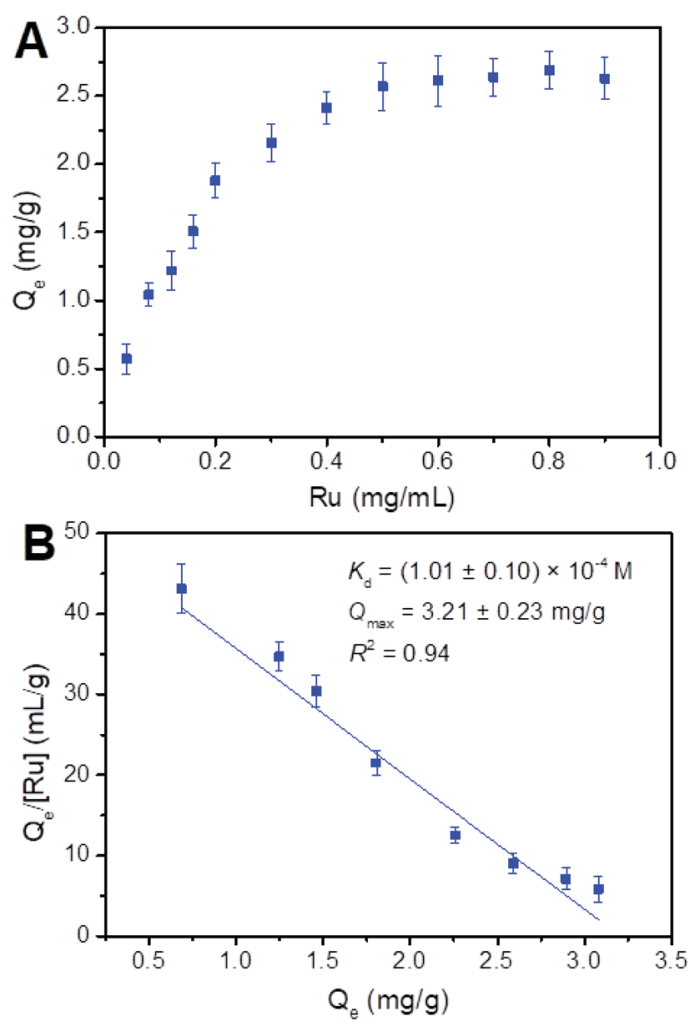

Fig. 6 Binding isotherms (A) and Scatchard plots (B) for the binding of $\mathrm{Fe}_{3} \mathrm{O}_{4} @ \mathrm{PEl} @ \mathrm{CBO}$ with rutin (Ru). 

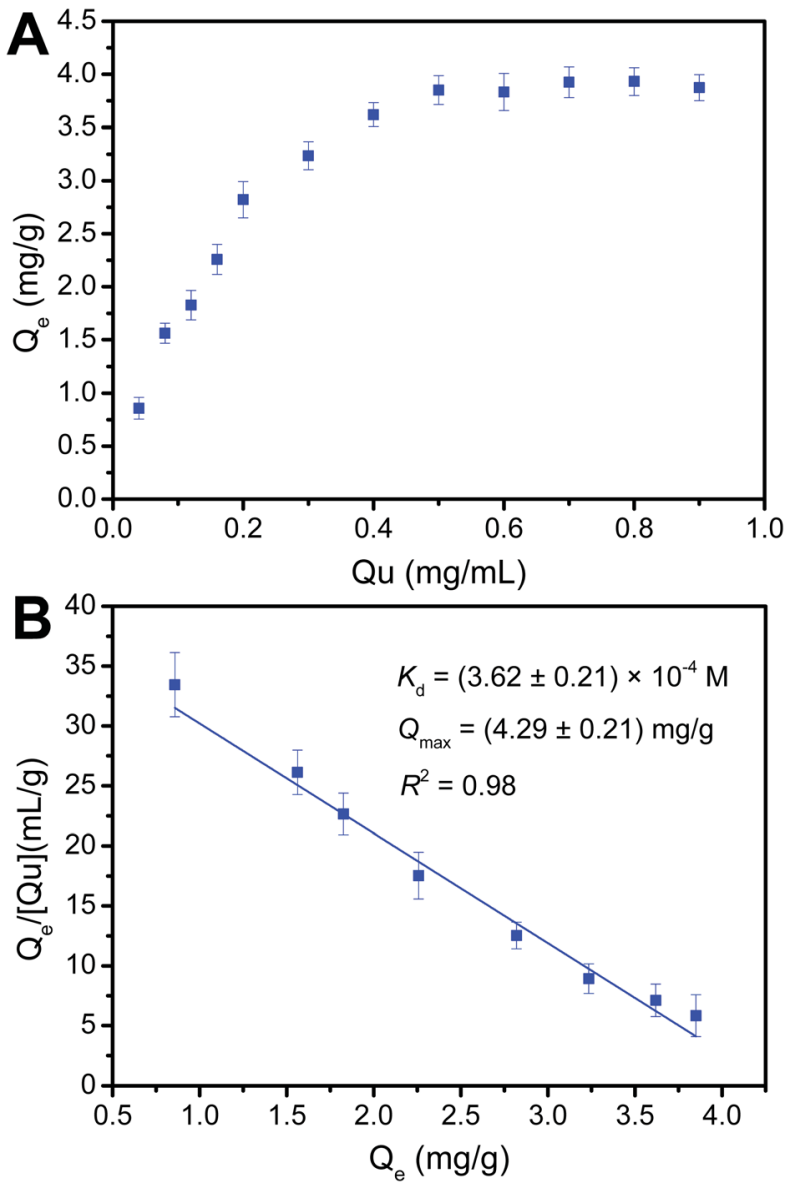

Fig. 7 Binding isotherms (A) and Scatchard plots (B) for the binding of $\mathrm{Fe}_{3} \mathrm{O}_{4} @ \mathrm{PEl} @ \mathrm{CBO}$ with quercetin (Qu).

explanation is that as rutin contains a pair of cis-diols, there is synergistic effect on the $\mathrm{Fe}_{3} \mathrm{O}_{4} @ P E I @ C B O$ to some extent, which can greatly improve binding strength of $\mathrm{Fe}_{3} \mathrm{O}_{4}$ @PEI@CBO toward rutin. In contrast, quercetin contains only one cis-diol group, there is no synergistic effect on the $\mathrm{Fe}_{3}$ $\mathrm{O}_{4} @$ PEI@CBO. Clearly, the reason for the lower binding constant of the $\mathrm{Fe}_{3} \mathrm{O}_{4} @ \mathrm{PEI} @ \mathrm{CBO}$ toward quercetin is the absence of synergistic effect of multiple binding. In addition, the $K_{\mathrm{d}}$ value for rutin is also a little lower than those the previous boronate affinity materials provided for other single cis-diol such as adenosine ${ }^{45,46}$ due to synergistic effect.

However, although rutin exhibited higher binding affinity than quercetin for $\mathrm{Fe}_{3} \mathrm{O}_{4} @ \mathrm{PEI} @ \mathrm{CBO}$, the $Q_{\max }$ of rutin was a little lower than that of quercetin (Table 1). This is because that rutin occupies more binding sites of boronic acid moieties as compared with quercetin.

Table 1 Dissociation constants $\left(K_{\mathrm{d}}\right)$ and binding capacity $\left(Q_{\max }\right)$ of $\mathrm{Fe}_{3} \mathrm{O}_{4} @ \mathrm{PE} \mathrm{Q} \mathrm{aCBO}$ for $\mathrm{Ru}$ and $\mathrm{Qu}$

\begin{tabular}{llll}
\hline & $K_{\mathrm{d}}(\mathrm{M})$ & $Q_{\max }\left(\mu \mathrm{mol} \mathrm{g}^{-1}\right)$ & $R^{2}$ \\
\hline $\mathrm{Ru}$ & $(1.01 \pm 0.10) \times 10^{-4}$ & $3.21 \pm 0.23$ & 0.94 \\
$\mathrm{Qu}$ & $(3.62 \pm 0.21) \times 10^{-4}$ & $4.29 \pm 0.21$ & 0.98
\end{tabular}

In a word, the amplified number of boronic acid moieties by using PEI as a scaffold can improve greatly the binding affinity of $\mathrm{Fe}_{3} \mathrm{O}_{4} @$ PEI@CBO toward flavonoids with multiple cis-diols but fails to improve even reduce the binding capacity.

\section{Adsorption time}

An appropriate adsorption time to obtain high binding capacity is required in the extraction and separation procedure. The effect of extraction time on the extraction efficiency of flavonoids was investigated by varying from $1 \mathrm{~min}$ to 10 min (Fig. 8). As depicted in Fig. 8, the binding capacity of $\mathrm{Ru}$ or Qu onto $\mathrm{Fe}_{3} \mathrm{O}_{4} @ P E I @ C B O$ had a fast adsorption rate within the first 2 min because amount of binding sites at the beginning enabled $\mathrm{Ru}$ or $\mathrm{Qu}$ to be easily adsorbed to $\mathrm{Fe}_{3}$ $\mathrm{O}_{4} @$ @PI@CBO with less resistance. Besides, the binding capacity reached a maximum value at an adsorption time of $3 \mathrm{~min}$. When the extraction time was increased from 3 to $6 \mathrm{~min}$, the binding capacity remained essentially constant. These results indicate that extraction equilibrium could be achieved in $3 \mathrm{~min}$, implying that most of the binding sites had been occupied by Ru or Qu in such a situation. This total adsorption time in the prepared boronate affinity materials is much shorter than that in other boronate affinity materials (30-90 min)..$^{51-55}$ This may be ascribed to its excellent adsorption of flavonoids during the extraction. In the light of these results, 3 min was chosen as the optimum adsorption time for extraction. This result indicates that the mass transfer speed in the $\mathrm{Fe}_{3} \mathrm{O}_{4} @ \mathrm{PEI} @ \mathrm{CBO}$ prepared by the proposed method was fast.

\section{The lowest extractable concentration of rutin and quercetin}

As we know, binding strength can determine how low extractable concentration of cis-diol-containing flavonoids. $\mathrm{As}^{\mathrm{Fe}_{3}-}$ $\mathrm{O}_{4} @ P E I @ C B O$ exhibited significantly increased binding affinity towards rutin due to the amplified number of boronic acid

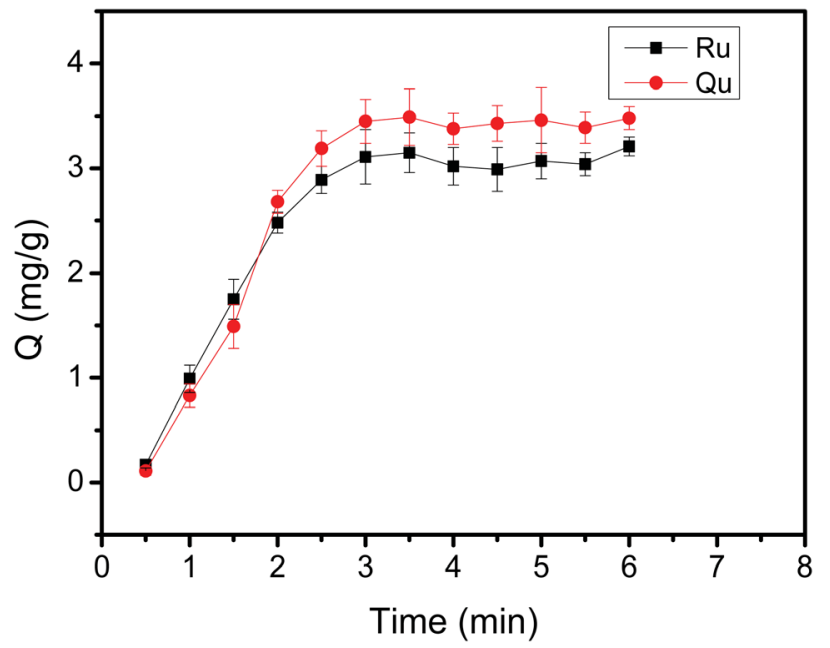

Fig. 8 Binding equilibrium of $\mathrm{Fe}_{3} \mathrm{O}_{4}$ (APEI@CBO with $\mathrm{Ru}$ and $\mathrm{Qu}$. Sample: $0.50 \mathrm{mg} \mathrm{mL}^{-1}$ Ru containing $50 \mathrm{mM}$ phosphate, $\mathrm{pH} 7.0$. 
moieties, $\mathrm{Fe}_{3} \mathrm{O}_{4} @ \mathrm{PEI} @ \mathrm{CBO}$ were able to extract rutin of lower concentration than quercetin. To investigate the lowest extractable concentration of rutin and quercetin, UV-vis absorbance was used. As shown in Fig. 9, for rutin and quercetin standard solutions, the lowest detectable concentrations were $0.3 \mu \mathrm{g} \mathrm{mL}{ }^{-1}(\mathrm{~S} / \mathrm{N}=5.0)$ and $0.2 \mu \mathrm{g} \mathrm{mL}^{-1}(\mathrm{~S} / \mathrm{N}=7.0)$, respectively. When the detection was combined with the $\mathrm{Fe}_{3} \mathrm{O}_{4}$ @PEI@CBO extraction, the lowest detectable concentrations for rutin and quercetin were lowered to $0.003 \mu \mathrm{g} \mathrm{mL}{ }^{-1}(\mathrm{~S} / \mathrm{N}=12)$ and $0.01 \mu \mathrm{g} \mathrm{mL}{ }^{-1}(\mathrm{~S} / \mathrm{N}=12)$, respectively. The results indicated that the $\mathrm{Fe}_{3} \mathrm{O}_{4} @ \mathrm{PEI} @ \mathrm{CBO}$ were able to extract lower concentration of rutin as compared with other single cis-diol such as quercetin.

\section{Effect of competing saccharides on the extraction of flavonoids by $\mathrm{Fe}_{3} \mathrm{O}_{4} @ \mathrm{PEI} @ \mathrm{CBO}$}

Sugars, cis-diol-containing compounds, are present in real samples such as in fruits, vegetables, herbaceous plants, tea, honey, coffee and, thus, their competing binding with boronic acids may result in reduced extraction capabilities of boronic acid-functionalized materials towards flavonoids. The $\mathrm{Fe}_{3}$ $\mathrm{O}_{4} @ P E I @ C B O$ exhibited much higher binding affinity towards flavonoids as compared with their affinity towards saccharides

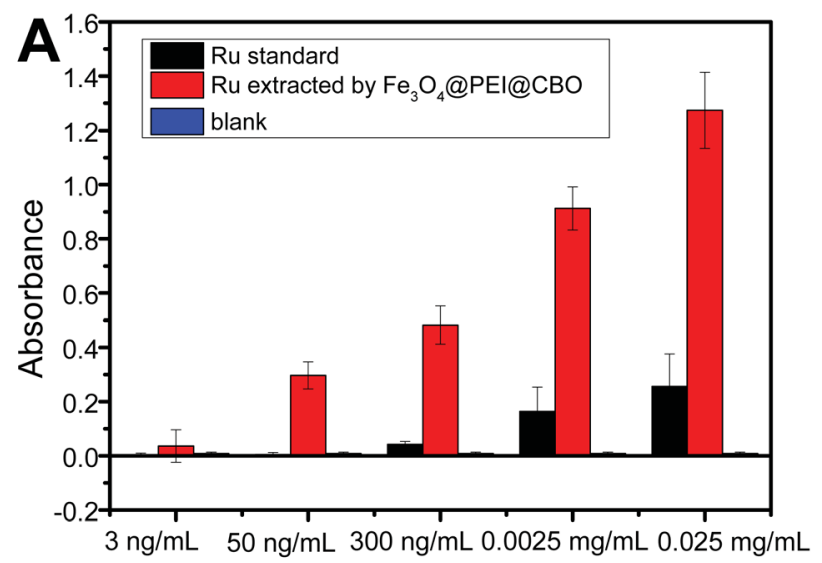

[Ru]

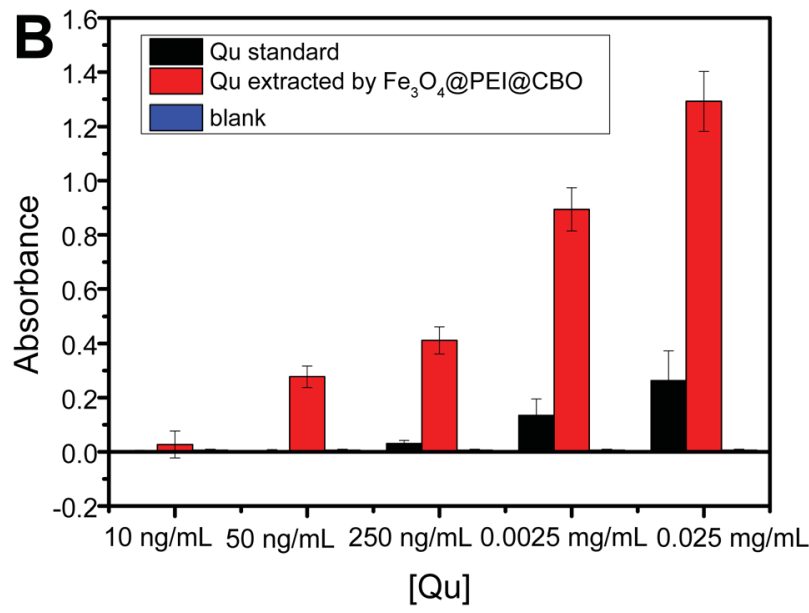

Fig. 9 The lowest extractable concentration of $\mathrm{Ru}(\mathrm{A})$ and $\mathrm{Qu}(\mathrm{B})$. because flavonoids contain phenols while saccharides contains aliphatic alcohol. Thus, the $\mathrm{Fe}_{3} \mathrm{O}_{4} @ P E I @ C B O$ was very tolerant of the interference of competing saccharides. As shown in Fig. 10, even in the presence of a competing monosaccharide at 100-fold higher concentration, the $\mathrm{Ru}$ and $\mathrm{Qu}$ amount extracted by the $\mathrm{Fe}_{3} \mathrm{O}_{4} @ P E I @ C B O$ was $84-97 \%$ and $66-89 \%$ of that when no sugar was present, respectively, depending on the nature of the competing saccharide. Clearly, the binding of $\mathrm{Ru}$ to $\mathrm{Fe}_{3} \mathrm{O}_{4} @ \mathrm{PEI} @ \mathrm{CBO}$ is affected less than that of $\mathrm{Qu}$ to $\mathrm{Fe}_{3} \mathrm{O}_{4} @ \mathrm{PEI} @ \mathrm{CBO}$ by the presence of the competing saccharide.

\section{Binding pH}

Binding $\mathrm{pH}$ is an important binding property of boronic acidfunctionalized materials. As most commercially available boronic acid ligands are generally weak acids with a $\mathrm{p} K_{\mathrm{a}}$ of $8-9$, conventional boronic acid-functionalized nanomaterials require a basic binding $\mathrm{pH}$. It is a common sense that the binding affinity of boronate affinity materials increased with increasing the $\mathrm{pH}$. Therefore, the binding affinity is certainly better at alkaline $\mathrm{pH}$ than neutral $\mathrm{pH}$ or acidic $\mathrm{pH}$. However, the basic $\mathrm{pH}$ is easy to oxidize the cis-diols of cis-diol-containing flavonoids. To address this issue, relatively low binding $\mathrm{pH}$
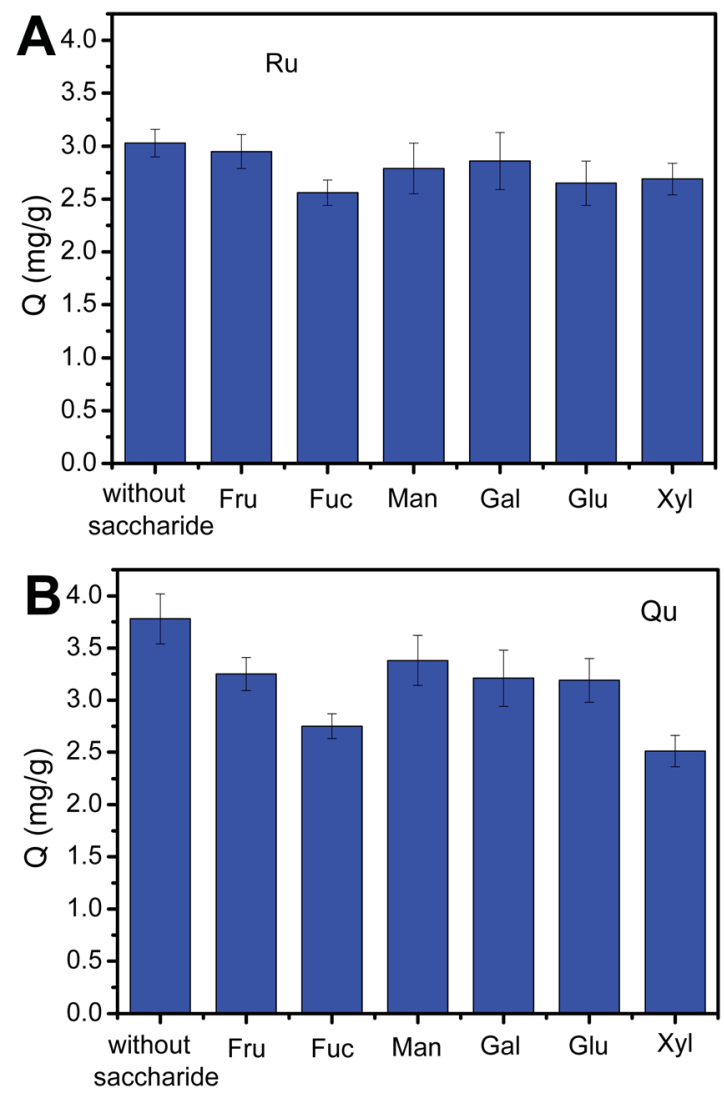

Fig. 10 Effect of competing saccharides on the $\mathrm{Ru}(\mathrm{A})$ and $\mathrm{Qu}(\mathrm{B})$ amount extracted by the $\mathrm{Fe}_{3} \mathrm{O}_{4}$ (aPEl (aCBO. Samples: (A) $2 \mu \mathrm{g} \mathrm{mL} \mathrm{L}^{-1} \mathrm{Ru}$ without or with $0.2 \mathrm{mg} \mathrm{mL}^{-1}$ saccharide; (B) $2 \mu \mathrm{g} \mathrm{mL}^{-1}$ Qu without or with $0.2 \mathrm{mg} \mathrm{mL}^{-1}$ saccharide, fructose (Fru), fucose (Fuc), mannose (Man), galactose (Gal), glucose (Glu), xylose (Xyl). 
should be applied. Several boronic acid ligands with electronwithdrawing groups, such as DFFPBA and 3-carboxybenzoboroxole $^{24,47}$ reduced the binding $\mathrm{pH}$ to neutral or acidic conditions. Thus, the prepared boronic acid-functionalized MNPs using 3-carboxybenzoboroxole as a ligand and PEI as a scaffold can provide a lower binding $\mathrm{pH}$. As depicted in Fig. 11, the $\mathrm{Fe}_{3} \mathrm{O}_{4} @ P E I @ C B O$ NPs exhibit high binding capacity and can well capture rutin or quercetin at $\mathrm{pH} \geq 6.0$. When the $\mathrm{pH}$ is higher than 6.0, the binding capacity of $\mathrm{Fe}_{3} \mathrm{O}_{4} @ \mathrm{PEI} @ \mathrm{CBO}$ for rutin is lower than that for quercetin because one rutin molecule can occupy two boronic acid sites and one quercetin molecule can occupy only one boronic acid site. However, when the $\mathrm{pH}$ is lower than 5.0 , the binding capacity of $\mathrm{Fe}_{3} \mathrm{O}_{4}$ @PEI@CBO for rutin is higher than that for quercetin because binding affinity dominates binding capacity under lower $\mathrm{pH}$ conditions.

\section{Reproducibility and reusability}

The reproducibility of the obtained $\mathrm{Fe}_{3} \mathrm{O}_{4} @ P E I @ C B O$ was investigated by using six batches of $\mathrm{Fe}_{3} \mathrm{O}_{4} @ P E I @ C B O$ prepared on different days, and the measurements replicated three times in parallel. By calculation, the average $Q$ of the total six batches of $\mathrm{Fe}_{3} \mathrm{O}_{4} @ \mathrm{PEI} @ \mathrm{CBO}$ for $\mathrm{Ru}$ and Qu were 3.02 and $3.85 \mathrm{mg} \mathrm{g}^{-1}$, and the relative standard deviations (RSD) were less than $5.1 \%$ $(3.8 \%, 4.6 \%, 4.8 \%, 4.2 \%$, and $5.1 \%)$ for $\mathrm{Ru}$ and less than $6.1 \%$ $(5.3 \%, 4.5 \%, 6.1 \%, 5.8 \%, 4.9 \%$, and $5.8 \%)$ for Qu. The results indicated that the reproducibility of the $\mathrm{Fe}_{3} \mathrm{O}_{4} @ \mathrm{PEI} @ \mathrm{CBO}$ was satisfactory.

A stable adsorption performance is one of the most important properties of boronate affinity materials in real application. The $\mathrm{Fe}_{3} \mathrm{O}_{4} @ \mathrm{PEI} @ \mathrm{CBO}$ could be reused after washing with acid solution. The adsorption-regeneration cycle was repeated ten times with the same $\mathrm{Fe}_{3} \mathrm{O}_{4} @ \mathrm{PEI} @ \mathrm{CBO}$ to evaluate the stability of the $\mathrm{Fe}_{3} \mathrm{O}_{4} @ \mathrm{PEI} @ \mathrm{CBO} . \mathrm{Fe}_{3} \mathrm{O}_{4} @$ @PEI@CBO are very stable and adsorption capacity still maintain at almost a steady value of $92.6 \%$ of the first cycle after five adsorption-desorption cycles. That's, the $\mathrm{Fe}_{3} \mathrm{O}_{4} @$ PEI@CBO could be well reused at least five times.

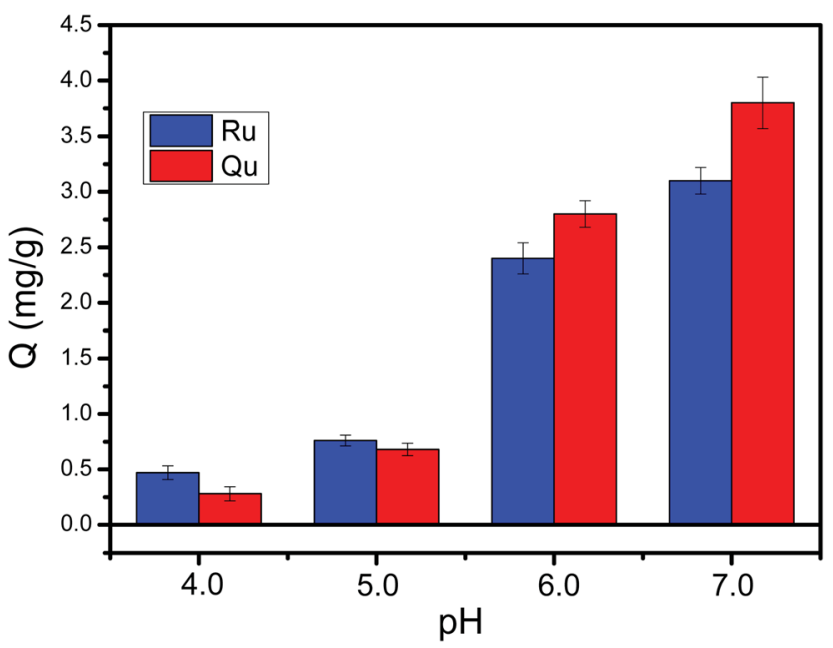

Fig. $11 \mathrm{pH}$ on the effect of the binding capacity of $\mathrm{Fe}_{3} \mathrm{O}_{4}$ (aPEl@CBO towards Ru and Qu.

\section{Conclusions}

In this study, the high boronate avidity SNPs were prepared for the selective enrichment of trace glycoproteins. By using branched PEI as the scaffold for amplification of boronic acid sites and 3-carboxybenzoboroxole as the affinity ligand, high boronate avidity was obtained owing to PEI-assisted synergistic multivalent binding. The obtained binding constant is $10^{-7} \mathrm{M}$, which was the highest among already reported boronic acidfunctionalized materials except MIPs. Besides, PEI-assisted synergistic effect can lead to lower binding $\mathrm{pH}$. Due to the enhanced binding strength and the lower binding $\mathrm{pH}$, the boronate avidity MNPs can be directly applied to selective enrichment of trace glycoproteins from real samples.

\section{Conflicts of interest}

There are no conflicts to declare.

\section{Acknowledgements}

We are grateful to the National Natural Science Foundation of China (no. 21804003), the Key Research Projects of Henan Higher Education Institutions (no. 18A150038) and the Henan Scientific and Technological Research Projects (no. 182102310713) for financial support for this work.

\section{References}

1 S. Kumar and A. K. Pandey, Sci. World J., 2013, 2013, 1-16.

2 F. D. Romagnolo and O. I. Selmin, J. Nutr. Gerontol. Geriatr., 2012, 31, 206-238.

3 A. N. Panche, A. D. Diwan and S. R. Chandra, J. Nutr. Sci., 2016, 5, e47.

4 J. Robak and R. J. Gryqlewski, Pol. J. Pharmacol., 1996, 48, 555-564.

5 P. E. Mladěnka, L. E. Zatloukalová, T. Filipsky and R. Hrdina, Curr. Med. Chem., 2016, 49, 963-975.

6 M. Meireles, E. Moura, M. A. Vieira-Coelho, C. SantosBuelga, S. Gonzalez-Manzano, M. Dueñas, N. Mateus, A. Faria and C. Calhau, Mol. Nutr. Food Res., 2016, 60, 495501.

7 A. De Villiers, P. Venter and H. Pasch, J. Chromatogr. A, 2016, 1430, 16-78.

8 J. Chen, Y. Wu, J. Zou and K. Gao, Bioorg. Med. Chem., 2016, 24, 1488-1494.

9 A. González-Sarrías, M. Á. Núñez-Sánchez, F. A. TomásBarberán and J. C. Espín, J. Agric. Food Chem., 2017, 65, 752-758.

10 M. Lu, J. Ji, Y. Jiang, Z. Chen, Z. Yuan, Q. You and Z. Jiang, Sci. Rep., 2016, 6, 26585-26598.

11 W. Zhou, N. Yao, G. P. Yao, C. H. Deng, X. M. Zhang and P. Y. Yang, Chem. Commun., 2008, 557, 7-5579.

12 M. Chen, Y. Lu, Q. Ma, L. Guo and Y. Q. Feng, Analyst, 2009, 134, 2158-2164.

13 J. Tang, Y. Liu, P. Yin, G. P. Yao, G. Q. Yan, C. H. Deng and X. M. Zhang, Proteomics, 2010, 10, 2000-2014. 
14 Z. A. Lin, J. L. Pang, H. H. Yang, Z. W. Cai, L. Zhang and G. N. Chen, Chem. Commun., 2011, 47, 9675-9677.

15 F. Yang, Z. A. Lin, X. W. He, L. X. Chen and Y. K. Zhang, J. Chromatogr. A, 2011, 1218, 9194-9201.

16 Z. A. Lin, J. L. Pang, Y. Lin, H. Huang, Z. W. Cai, L. Zhang and G. N. Chen, Analyst, 2011, 136, 3281-3288.

17 Z. J. Liu, K. Ullah, L. P. Su, F. Lv, Y. L. Deng, R. J. Dai, Y. J. Li and Y. K. Zhang, J. Mater. Chem., 2012, 22, 18753-18756.

18 L. T. Liu, Y. Zhang, L. Zhang, G. Q. Yan, J. Yao, P. Y. Yang and H. J. Lu, Anal. Chim. Acta, 2012, 753, 64-72.

19 Y. Y. Qu, X. Liu, Z. Liang, L. H. Zhang and Y. K. Zhang, Chem. - Eur. J., 2012, 18, 9056.

20 Z. F. Xu, K. M. A. Uddin and L. Ye, Macromolecules, 2012, 45, 6464.

21 X. T. Shen, C. G. Xu, K. M. A. Uddin, P. O. Larsson and L. Ye, J. Mater. Chem. B, 2013, 1, 4612-4618.

22 F. Yang, J. Mao, X. W. He, L. X. Chen and Y. K. Zhang, Anal. Bioanal. Chem., 2013, 405, 5321-5331.

23 H. Li, Y. H. Shan, L. Z. Qiao, A. Dou, X. Z. Shi and G. W. Xu, Anal. Chem., 2013, 85, 11585-11592.

24 G. B. Xu, W. Zhang, L. M. Wei, H. J. Lu and P. Y. Yang, Analyst, 2013, 138, 1876-1885.

25 S. T. Zhang, X. W. He, L. X. Chen and Y. K. Zhang, New J. Chem., 2014, 38, 4212-4218.

26 X. H. Zhang, J. W. Wang, X. W. He, L. X. Chen and Y. K. Zhang, ACS Appl. Mater. Interfaces, 2015, 7, 2457624584.

27 J. W. Wang, X. W. He, L. X. Chen and Y. K. Zhang, RSC Adv., 2016, 6, 47055-47061.

28 X. Y. An, X. W. He, L. X. Chen and Y. K. Zhang, J. Mater. Chem. B, 2016, 4, 6125-6133.

29 J. A. Yang, X. W. He, L. X. Chen and Y. K. Zhang, J. Chromatogr. A, 2017, 1513, 118-125.

30 L. F. Chang, X. W. He, L. X. Chen and Y. K. Zhang, Sens. Actuators, B, 2017, 243, 72-77.

31 D. J. Li, Y. Chen and Z. Liu, Chem. Soc. Rev., 2015, 44, 80978123.

32 D. J. Li, Z. J. Bie, F. F. Wang and E. H. Guo, Analyst, 2018, 143, 4936-4943.

33 D. J. Li, H. J. Xia and L. Wang, Talanta, 2018, 184, 235-243.

34 D. J. Li, T. Y. Tu, M. K. Yang and C. Xu, Talanta, 2018, 184, 316-324.
35 D. J. Li and Z. J. Bie, Analyst, 2017, 142, 4494-4502.

36 D. J. Li, Q. Yuan, W. L. Yang, M. K. Yang, S. H. Li and T. Y. Tu, Anal. Biochem., 2018, 561-562, 18-26.

37 D. J. Li, T. Y. Tu and X. Y. Wu, Anal. Methods, 2018, 10, 44194429.

38 S. C. Liu, J. M. Pan, H. J. Zhu, G. Q. Pan, F. X. Qiu, M. J. Meng, J. T. Yao and D. Yuan, Chem. Eng. J., 2016, 290, 220-231.

39 A. Matsumoto, K. Yamamoto, R. Yoshida, K. Kataoka, T. Aoyagi and Y. Miyahara, Chem. Commun., 2010, 46, 2203-2205.

40 X. Li, J. Pennington, J. F. Stobaugh and C. Schoeich, Anal. Biochem., 2008, 372, 227-236.

41 X. C. Liu and W. H. Scouten, J. Mol. Recognit., 1996, 9, 462467.

42 G. Wulff, M. Lauer and H. Bohnke, Angew. Chem., Int. Ed., 1984, 23, 741-742.

43 M. Dowlut and D. G. Hall, J. Am. Chem. Soc., 2006, 128, 42264227.

44 A. Pal, M. Berube and D. G. Hall, Angew. Chem., Int. Ed., 2010, 49, 1492-1495.

45 L. K. Mohler and A. W. Czarnik, Ribonucleoside membrane transport by a new class of synthetic carrier, J. Am. Chem. Soc., 1993, 115, 2998-2999.

46 F. C. Fischer and E. Havinga, Recl. Trav. Chim. Pays-Bas, 1974, 93, 21-24.

47 H. Y. Li, H. Y. Wang, Y. C. Liu and Z. Liu, Chem. Commun., 2012, 48, 4115.

48 Z. J. Bie, Y. Chen, H. Y. Li, R. H. Wu and Z. Liu, Anal. Chim. Acta, 2014, 834, 1-8.

49 Q. Wu, B. Jiang, Y. J. Weng, J. X. Liu, S. W. Li, Y. C. Hu, K. G. Yang, Z. Liang, L. Zhang and Y. Zhang, Anal. Chem., 2018, 90, 2671-2677.

50 L. Y. Wang, J. Bao, L. Wang, F. Zhang and Y. D. Li, Chem. Eur. J., 2006, 12, 6341-6347.

51 X. D. Bi and Z. Liu, Anal. Chem., 2014, 86, 959-966.

52 X. D. Bi and Z. Liu, Anal. Chem., 2014, 86, 12382-12389.

53 Z. A. Lin, L. X. Sun, W. Liu, Z. W. Xia, H. H. Yang and G. N. Chen, J. Mater. Chem. B, 2014, 2, 637-643.

54 Y. Hao, R. X. Gao, D. C. Liu, G. Y. He, Y. H. Tang and Z. J. Guo, Talanta, 2016, 153, 211-220.

55 Y. X. Li, M. Hong, M. Miao, Q. Bin, Z. Y. Lin, Z. W. Cai and G. N. Chen, J. Mater. Chem. B, 2013, 1, 1044-1051. 